\title{
Sex-dependent hepatic transcripts and metabolites in the development of glucose intolerance and insulin resistance in Zucker diabetic fatty rats
}

\author{
Carolina Gustavsson, Tomoyoshi Soga1, Erik Wahlström, Mattias Vesterlund, \\ Alireza Azimi, Gunnar Norstedt and Petra Tollet-Egnell \\ Department of Molecular Medicine and Surgery, Karolinska Institutet, Stockholm, Sweden \\ ${ }^{1}$ Institute for Advanced Biosciences, Keio University, Tokyo, Japan \\ (Correspondence should be addressed to P Tollet-Egnell; Email: petra.tollet.egnell @ki.se)
}

\begin{abstract}
Male Zucker diabetic fatty (mZDF) rats spontaneously develop type 2 diabetes, whereas females only become diabetic when fed a diabetogenic high-fat diet (high-fat-fed female ZDF rat, HF-fZDF). The aim of this study was to investigate if differences in liver functions could provide clues to this sex difference. Non-diabetic obese fZDF rats were compared with either mZDF or HF-fZDF regarding hepatic molecular profiles, to single out those components that might be protective in the females. High-fat feeding in fZDF led to enhanced weight gain, increased blood glucose and insulin levels, reduced insulin sensitivity and a trend towards reduced glucose tolerance, indicative of a prediabetic state. mZDF rats were diabetic, with low levels of insulin, high levels of glucose, reduced insulin sensitivity and impaired glucose tolerance. Transcript profiling and capillary electrophoresis time-of-flight mass spectrometry were used to indentify hepatic transcripts and metabolites that might be related to this. Many diet-induced alterations in transcript and metabolite levels in female rats were towards a 'male-like' phenotype, including reduced lipogenesis, increased fatty acid (FA) oxidation and increased oxidative stress responses. Alterations detected at the level of hepatic metabolites, indicated lower capacity for glutathione (GSH) production in male rats, and higher GSH turnover in females. Taken together, this could be interpreted as if anabolic pathways involving lipogenesis and lipid output might limit the degree of FA oxidation and oxidative stress in female rats. Together with a greater capacity to produce GSH, these hepatic sex differences might contribute to the sex-different development of diabetes in ZDF rats.
\end{abstract}

Journal of Molecular Endocrinology (2011) 47, 129-143

\section{Introduction}

Female sex during adolescence has been shown to exert a positive influence on insulin sensitivity, lipids and blood pressure (Moran et al. 2008), which is in line with the notion that premenopausal women have a lower risk of developing the metabolic syndrome compared with age-matched men (Isomaa $e t$ al. 2001, Legato $e t$ al. 2006, Regitz-Zagrosek et al. 2007). No single risk factor or combination of factors has yet been shown to fully explain this, but the fact that risk protection disappears after menopause strongly suggests that female hormones play a protective role. Oestrogens exert many physiological effects that might influence both cardiovascular risk and insulin resistance, including antiinflammatory (Arenas et al. 2005) and antioxidant (Louet et al. 2004, Baba et al. 2005, Borrás et al. 2005) properties. Oestrogens have also been shown to inhibit lipogenesis and stimulate lipolysis in abdominal visceral fat depots, to promote use of lipid as a fuel by muscle (D'Eon et al. 2005) and reduce central adiposity (Perrone et al. 1999). Both abdominal visceral obesity and non-alcoholic fatty liver disease (NAFLD) are closely associated with metabolic disorders and are more common in men (Cheung \& Sanyal 2010). Furthermore, male gender has been shown to be independently associated with NAFLD in non-obese subjects (Kim et al. 2004). Experiments in animals indicate that downstream effects of sexdependent hormones within the liver play a role during development of NAFLD and insulin resistance. For example, it was shown that oestrogen receptor $\alpha$ knockout mice develop fatty liver, hepatic insulin resistance and impaired glucose tolerance (Bryzgalova et al. 2006).

High-fat or high-carbohydrate diets can be used in animal models to induce the metabolic changes observed in the metabolic syndrome. A high-sucrose diet has been shown to induce insulin resistance and other components of the metabolic syndrome in male rats and ovariectomised females, whereas females are unaffected (Horton et al. 1997). Similarly, oestrogens have been shown to protect against high-fat diet-induced insulin resistance and glucose intolerance

DOI: 10.1530/JME-11-0007 Online version via http://www.endocrinology-journals.org 
(Riant et al. 2009), again suggesting that female hormones can protect against developing components of the metabolic syndrome. The obese Zucker diabetic fatty (ZDF/Gmi-fa) male rat has become a widely used animal model of type 2 diabetes (T2D), in contrast to the obese ZDF female that rarely develop the disease (Clark et al. 1983). The males spontaneously develop insulin resistance and hyperglycaemia by 8 weeks and diabetes by 12 weeks of age, whereas the females only become diabetic when fed a diabetogenic high-fat diet (Corsetti et al. 2000). Furthermore, a significant difference between males and females developing diabetes as a function of dietary fat content is accompanied by a difference in triglyceride/apolipoprotein B ratios (Corsetti et al. 2000), with females secreting more triglyceride-enriched lipoprotein particles. This is in line with results obtained in healthy Sprague-Dawley (SD) rats, with females expressing higher levels of lipogenic genes in their livers (Gustavsson et al. 2010) as well as having a greater capacity for hepatic uptake of long-chain fatty acids (FAs), synthesis of triglycerides and assembly of very-low-density lipoprotein (VLDL) particles (SolerArgilaga et al. 1975, Soler-Argilaga \& Heimberg 1976, Kushlan et al. 1981).

NAFLD is believed to be caused by fat accumulation in the liver and through increased production of reactive oxygen species (ROS) lead to hepatic insulin resistance (Houstis et al. 2006). The exact mechanisms of oxidative stress in fatty livers are not known, but an increase in pro-oxidant production and/or an increase in the amount of lipid substrate susceptible for peroxidative attack may exhaust the antioxidant defences and induce oxidative stress. If female livers are more efficient in packaging FAs into VLDL particles (Kushlan et al. 1981), this might contribute to a reduced hepatocellular load of lipids and a lower risk of developing NAFLD, oxidative stress and insulin resistance. On the contrary, male rats are more responsive to peroxisome proliferators than female rats, leading to greater effects on peroxisome proliferator-activated receptor (PPAR)-mediated gene expression and higher rates of lipid oxidation (Svoboda et al. 1969, Hawkins et al. 1987, Kawashima et al. $1989 a, b)$. This might lead to a greater production of ROS during situations of increased hepatic lipid load. Furthermore, we have recently shown that healthy SD male rats have a greater hepatic turnover of carbohydrates, including higher levels of glycogen, higher expression of gluconeogenic genes and higher hepatic glucose output (Gustavsson et al. 2010). Taken together, it is possible that these differences in hepatic lipid and carbohydrate metabolism might contribute to a higher risk of developing hepatic insulin resistance and hyperglycaemia in males compared with females during situations of increased hepatic fat and/or insufficient insulin production.

With the assumption that sex-different development of T2D in obese ZDF rats to some degree depends on sex-different hepatic metabolism, we hypothesise that high-fat feeding in female ZDF rats would lead to a more male-like hepatic phenotype, including increased FA oxidation and ROS production, reduced lipogenesis and/or increased gluconeogenesis. By identifying the genes and downstream functions involved in this, it might be possible to unravel the protective components of the female liver. In this study, we have used transcript and metabolite profiling techniques to identify hepatic parameters that distinguish females developing glucose intolerance and insulin resistance, and compared those with components that characterise male diabetic animals.

\section{Materials and methods}

\section{Animals}

Ten 6-week-old male and 20 female ZDF rats (ZDF/Gmi-fa; Charles River, Koln, Germany) were maintained under standardised conditions, with free access to water and regular rodent chow (protein $26.8 \mathrm{kcal} \%$, carbohydrate $56.4 \mathrm{kcal} \%$, fat $16.7 \mathrm{kcal} \%$, Purina 5008, Charles River), for 1 week before the start of the experiment. The animals were divided into six groups ( $n=5$ per group), as described in Table 1 . Groups 1 and 4, were female rats maintained on regular chow (fZDF), groups 2 and 5 were female rats fed a diabetogenic high-fat diet (protein $12.6 \mathrm{kcal} \%$, carbohydrate $39 \cdot 2 \mathrm{kcal} \%$, fat $48 \cdot 1 \mathrm{kcal} \%$ fat, Purina $58 \mathrm{NX}$, Charles River; high-fat-fed female ZDF rat, HF-fZDF) and groups 3 and 6 were male rats maintained on regular chow (mZDF). Groups 1-3 were killed after 3 weeks and groups 4-6 after 6 weeks. At the end of study, $12 \mathrm{~h}$ fasted animals were killed and blood drawn from vena cava. Livers were removed, frozen in liquid nitrogen and stored at $-70{ }^{\circ} \mathrm{C}$ until further analysis. All animal experiments were approved by the regional ethics committee on Animal Experiments.

Table 1 Animal data. The table illustrates the grouping of the rats used in this study

\begin{tabular}{|c|c|c|c|}
\hline & Sex & Diet & Duration \\
\hline \multicolumn{4}{|l|}{ Group } \\
\hline 1 & Female & Standard & 3 weeks \\
\hline 2 & Female & High fat & \\
\hline 3 & Male & Standard & \\
\hline 4 & Female & Standard & 6 weeks \\
\hline 5 & Female & High fat & \\
\hline 6 & Male & Standard & \\
\hline
\end{tabular}




\section{Blood and serum analysis}

Blood was collected from vena cava in $10 \mathrm{ml}$ EDTA vacutainer tubes (Becton \& Dickinson, Stockholm, Sweden). Serum was obtained by centrifugation at $3000 \mathrm{~g}$ for $10 \mathrm{~min}$. The resulting supernatants were removed and analysed for insulin by RIA (Millipore, Stockholm, Sweden) and metabolites by capillary electrophoresis time-of-flight mass spectrometry (CETOFMS). A drop of blood was collected from the tip of the tail and analysed for blood glucose, using a Precision Xtra glucometer and test strips (Abbot, Solna, Sweden). Insulin-mediated effects on blood glucose levels were determined in $2 \mathrm{~h}$ fasted rats before and $40 \mathrm{~min}$ after s.c. injection with insulin ( $1 \mathrm{mU} / \mathrm{g}$ body weight).

\section{Intraperitoneal glucose tolerance test}

Intraperitoneal glucose tolerance tests (IPGTT) were performed in $10 \mathrm{~h}$ fasted rats ( $n=5$ per group) upon i.p. injections of $1 \mathrm{~g}$ glucose $/ \mathrm{kg}$ body weight. Glucose levels were assayed in a drop of blood from the tip of the tail at $-30,0,30,60,90$ and $120 \mathrm{~min}$ from the injection, using a Precision Xtra glucometer and test strips. The area under the curve (AUC)-IPGTT (concentration $\times$ time) was calculated by the trapezoidal method, as described before (Kim et al. 2009) and represented as $\mathrm{mmol} / \mathrm{l}$ and $\mathrm{h}$.

\section{Total RNA extraction}

Total RNA was isolated by homogenisation of frozen rat livers using a polytron PT-2000 (Kinematica, Littau, Switzerland) and SV Total RNA isolation kit (Promega) according to the protocol supplied by the manufacturer. The RNA concentration was determined using a NanoDrop ND-1000 Spectrophotometer (Thermo Fisher Scientific, Göteborg, Sweden). The quality of the RNA samples was examined using a RNA 6000 Nano Bioanalyzer according to the manufacturer's instructions (Agilent Technologies, Stockholm, Sweden). Only samples with a RNA integrity number above eight were accepted and used for further analysis.

\section{Expression profiling using microarrays}

Microarrays containing 70 mer oligonucleotide probes for 27649 rat protein-coding genes were fabricated and used to obtain transcript profiles, essentially as described earlier (Gustavsson et al. 2009). Each hybridisation compared fluorescent dye (e.g. Cy3)labelled cDNA reverse transcribed from RNA isolated from one group of rats with fluorescent dye (e.g. Cy5)labelled cDNA isolated from another group of rats; comparing either animals from groups 4 and 5 (13week-old fZDF and HF-fZDF) or animals from groups 4 and 6 (13-week-old fZDF and mZDF). Four out of five animals from each group were randomly assigned for this and each experiment was performed by individual samples $(n=4)$, using the same animals from group 4 for both hybridisations. Dye swapping was used so that half of the samples from each group were labelled with either Cy3 or Cy5, resulting in four hybridisations per group comparison. Identification of differentially expressed genes (due to sex and/or high-fat feeding) was performed by the SAM 1.21 (Significance Analysis for Microarray) software incorporated in Microsoft office Excel program. A 5\% false discovery rate (FDR) was used as a first cutoff. Genes with a $>1 \cdot 5$-fold increase or decrease were considered as being regulated (Ståhlberg et al. 2004), even though smaller changes in gene expression may also have important biological consequences. The results are represented as the mean of at least three independent determinations, allowing missing data from one out of four arrays. All data are available from the NCBI Gene Expression Omnibus database (GEO; http://www.ncbi.nlm.nih. gov/geo/) using the series entry GSE23810.

Functional annotation of the data was achieved through the use of Ingenuity Pathways Analysis (Ingenuity Systems, www.ingenuity.com). Transcripts from the dataset that met the mean fold change cutoff of 1.5 and were associated with a canonical pathway in Ingenuity's Knowledge Base were considered for the analysis. Fisher's exact test was used to calculate a $P$ value determining the probability that the association between the genes in the dataset and the canonical pathway is explained by chance alone. A heat map of log-2 expression values of significant genes was generated in MATLAB using the clustergram function BioinformaticsToolbox (Mathworks, Inc., Natick, MA, USA).

\section{Analysis of gene expression by real-time quantitative RT-PCR}

Total hepatic RNA was isolated, cDNA generated and gene expression quantified, as described earlier (Gustavsson et al. 2009). The primers for the genes of interest are shown in Table 2. The protocol was validated for each gene by checking melting curves for the absence of primer dimers or other unwanted amplicons. The levels of individual mRNAs were normalised with levels of the housekeeping gene acidic ribosomal phosphoprotein $\mathrm{P} \theta(A r b p)$ and the results expressed in arbitrary units.

\section{Immunoblotting}

Whole liver cell lysates were obtained by homogenising $100 \mathrm{mg}$ of liver in $1 \mathrm{ml}$ RIPA buffer $(50 \mathrm{mM}$ Tris-HCl, $\mathrm{pH} 7 \cdot 4,1 \%$ Triton X-100, $150 \mathrm{mM} \mathrm{NaCl}, 5 \mathrm{mM}$ EDTA, 
Table 2 Primer sequences for real-time PCR analysis

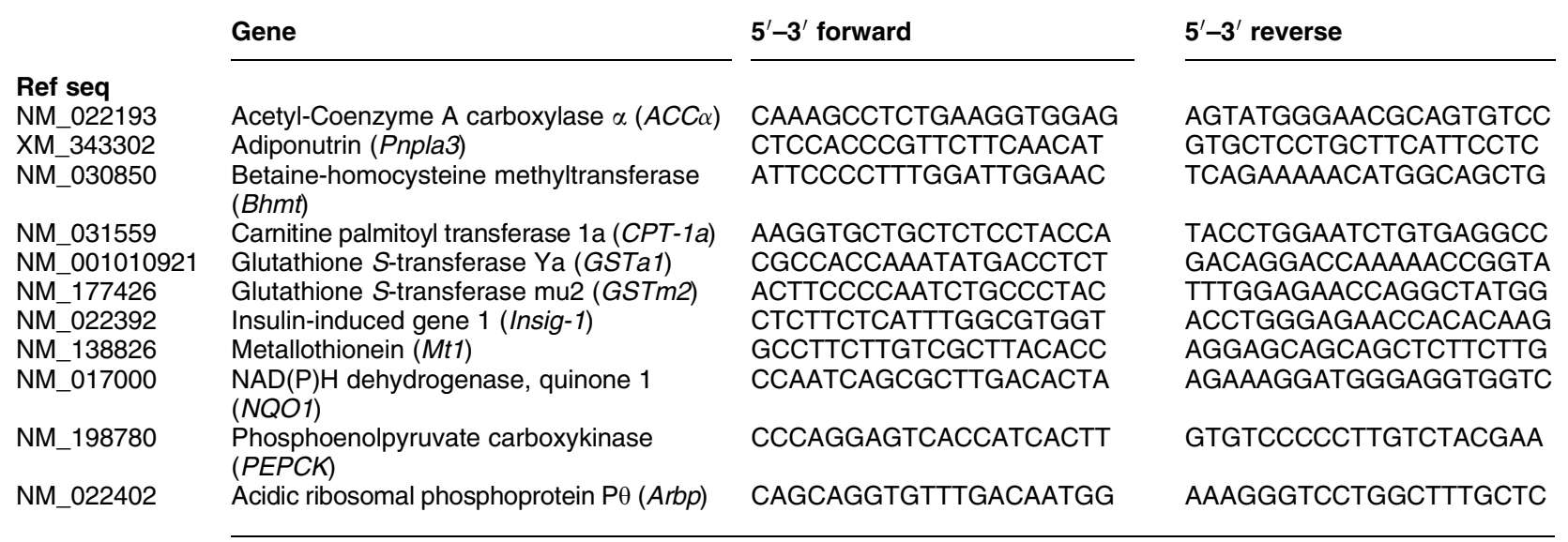

$1 \mathrm{mM}$ phenylmethylsulphonyl fluoride, $1 \mathrm{mM} \mathrm{Na} \mathrm{VO}_{4}$, $10 \mathrm{mM} \mathrm{NaF}, 1 \mu \mathrm{g} / \mathrm{ml}$ aprotinin, leupeptin and pepstatin), using a polytron PT-2000 (Kinematica AG), followed by $20 \mathrm{~min}$ of centrifugation $(12000 \mathrm{~g})$. The resulting supernatants were collected and proteins resolved by SDS-PAGE and transferred to PVDF membranes. The membranes were blocked for $1 \mathrm{~h}$ in Tris-buffered saline (TBS; $10 \mathrm{mM}$ Tris pH 8.0, $150 \mathrm{mM}$ $\mathrm{NaCl})$ containing $0 \cdot 1 \%(\mathrm{v} / \mathrm{v})$ Tween-20 and $5 \%(\mathrm{w} / \mathrm{v})$ BSA, incubated overnight at $4{ }^{\circ} \mathrm{C}$ with the antibody of interest diluted in TBST with 1\% BSA. Antibodies for detecting adiponutrin (PNPLA3; 1:1000) were from Everest Biotech (Oxfordshire, UK), c-Jun N-terminal kinase (JNK) and p-JNK (1:1000) from Cell Signaling Technology (Danvers, MA, USA) and $\beta$-actin (1:50 000) from Santa Cruz Biotechnology (Santa Cruz, CA, USA). The membranes were washed and incubated with secondary antibody for $1 \mathrm{~h}$ at room temperature according to the datasheet provided by the company. After additional washing steps, antibody binding was visualised using an ECL detection system (Pierce Biotechnology, Inc., Rockford, IL, USA). Densitometry analysis was performed by the software Quantity One 4.6.5 Basic (Bio-Rad, Hercules, CA, USA) to compare the amount of the antibody of interest to $\beta$-actin.

\section{Metabolite extraction}

Frozen liver tissue (30-60 mg) was completely homogenised by a cell disrupter (MS-100R; TOMY, Tokyo, Japan) at $2{ }^{\circ} \mathrm{C}$, after adding of $625 \mu \mathrm{l}$ methanol containing internal standards $(20 \mu \mathrm{M}$ each of L-methionine sulpone and D-camphor-10-sulphonic acid for cations, 2-morpholinoethanesulphonate for anions). The homogenate was removed and mixed with Milli-Q water and chloroform (2:5); $300 \mu$ l of the solution were transferred to another tube and chloroform was added. The mixture was centrifuged at $4600 \mathrm{~g}$ for $15 \mathrm{~min}$ at $4^{\circ} \mathrm{C}$. Subsequently, the upper aqueous layer was centrifugally filtered through a Millipore $5 \mathrm{kDa}$ cutoff filter to remove proteins. The filtrate was centrifugally concentrated and dissolved in Milli-Q water containing reference compounds $(200 \mu \mathrm{M}$ each of 3-aminopyrrolidine and trimesate) before CE-TOFMS analysis.

\section{Analysis of metabolites by CE-TOFMS}

\section{CE-TOFMS instrumentation}

All CE-TOFMS experiments were performed by an Agilent CE capillary electrophoresis system (Agilent Technologies, Waldbronn, Germany), an Agilent G3250AA LC/MSD TOF system (Agilent Technologies, Palo Alto, CA, USA), an Agilent1100 series binary HPLC pump and the G1603A Agilent CE-MS adapter and G1607A Agilent CE-ESI-MS sprayer kit. For system control and data acquisition, we used the G2201AA Agilent ChemStation software for CE and the Analyst QS for Agilent TOFMS software. CE-MS/MS analyses for compound identification were performed on a Q-Star XL Hybrid LC-MS/MS System (Applied Biosystems, Foster City, CA, USA) connected to an Agilent CE instrument.

\section{CE-TOFMS conditions for cationic metabolite analysis}

Separations were carried out in a fused silica capillary (50 $\mu \mathrm{m}$ i.d. $\times 100 \mathrm{~cm}$ total length) filled with $1 \mathrm{M}$ formic acid as the electrolyte (Soga \& Heiger 2000, Soga et al. 2006). Approximately $3 \mathrm{nl}$ of sample solution were injected at $50 \mathrm{mbar}$ for $3 \mathrm{~s}$ and $30 \mathrm{kV}$ of voltage was applied. The capillary temperature was maintained at $20^{\circ} \mathrm{C}$ and the sample tray was cooled below $5^{\circ} \mathrm{C}$. Methanol-water $(50 \% \mathrm{v} / \mathrm{v})$ containing $0.5 \mu \mathrm{M}$ reserpine was delivered as the sheath liquid at $10 \mu \mathrm{l} / \mathrm{m}$. ESITOFMS was operated in the positive ion mode and the 
capillary voltage was set at $4000 \mathrm{~V}$. A flow rate of heated dry nitrogen gas (heater temperature $300^{\circ} \mathrm{C}$ ) was maintained at 10 psig. In TOFMS, the fragmentor, skimmer and Oct RFV voltage were set at 75, 50 and $125 \mathrm{~V}$ respectively. Automatic recalibration of each acquired spectrum was performed by reference masses of reference standards. The methanol adduct ion $\left([2 \mathrm{MeOH}+\mathrm{H}]^{+}, m / z 65 \cdot 0597\right)$ and reserpine $([\mathrm{M}+$ $\left.\mathrm{H}]^{+}, m / z 609 \cdot 2806\right)$ provided the lock mass for exact mass measurements. Exact mass data were acquired at a rate of 1.5 cycles/s over a $50-1000 \mathrm{~m} / z$ range (Soga et al. 2006). CE-TOFMS conditions for anionic metabolite analysis: a chemically coated with a cationic polymer COSMO $(+)$ capillary (Nacalai Tesque, Kyoto, Japan) was used as the separation capillary. A $50 \mathrm{mM}$ ammonium acetate solution $(\mathrm{pH} 8.5)$ was used as electrolyte solution for CE separation (Soga et al. 2006). Sample solution $(30 \mathrm{nl})$ was injected at 50 mbar for $30 \mathrm{~s}$ and $-30 \mathrm{kV}$ of voltage was applied. Ammonium acetate $(5 \mathrm{mM})$ in $50 \%$ methanol-water $(\mathrm{v} / \mathrm{v})$ containing $0 \cdot 1 \mu \mathrm{M}$ hexakis was delivered as the sheath liquid at $10 \mu \mathrm{l} / \mathrm{m}$. ESI-TOFMS was conducted in the negative ion mode; the capillary voltage was set at $3500 \mathrm{~V}$. For TOFMS, the fragmentor, skimmer and Oct RFV voltage were set at 100, 50 and $200 \mathrm{~V}$ respectively. A flow rate of drying nitrogen gas (heater temperature $300{ }^{\circ} \mathrm{C}$ ) was maintained at $7 \mathrm{l} / \mathrm{min}$. Automatic recalibration of each acquired spectrum was performed by reference masses of reference standards $\left(\left[{ }^{13} \mathrm{C}\right.\right.$ isotopic ion of deprotonated acetic acid dimer $\left.\left(2 \mathrm{CH}_{3} \mathrm{COOH}-\mathrm{H}\right)\right]^{-}, \mathrm{m} / \mathrm{z}$ $120 \cdot 03841)$ and ([hexakis + deprotonated acetic acid $\left.\left(\mathrm{CH}_{3} \mathrm{COOH}-\mathrm{H}\right)\right]^{-}, \mathrm{m} / z$ 680.03554). Exact mass data were acquired at a rate of 1.5 spectra/s over a $50-1000$ $\mathrm{m} / \mathrm{z}$ range. Other conditions were described in the previous report (Soga et al. 2006). Data analysis was performed on the raw CE-TOFMS data using our proprietary software called MasterHands (Sugimoto et al. 2009, 2010a,b). Briefly, the peaks were detected from sliced electropherograms $(m / z 0.02$ width) and accurate $m / z$ values were calculated by Gaussian curve fitting. The migration times of the detected peaks were next normalised by a time-warping function, whose numerical parameters were optimised by a simplex method with peak matching across multiple datasets based on dynamic programming techniques (Sugimoto et al. 2010a,b). Any redundant features, such as isotopic peaks, fragments and adduct ions, were removed. Finally, the metabolites contained in the standard compounds were assigned to the remaining features by matching their $m / z$ values and normalised migration times.

Metabolites with a $>1 \cdot 2$-fold increase or decrease were considered as being affected by the diet and/or sex of the animal, and were further subjected to hierarchical clustering. Dendrograms and heat maps were generated using the Bioinformatics Toolbox in MATLAB.

\section{Statistical analysis}

Unless otherwise stated, all data were subjected to twoway ANOVA followed by Fisher's post hoc analysis and expressed as mean \pm s.E.M. Differences between groups were considered significant at $P<0 \cdot 05$.

\section{Results}

fZDF rats fed a diabetogenic high-fat diet (HF-fZDF) gained more weight and had higher $2 \mathrm{~h}$ fasted blood glucose levels than fZDF rats fed regular chow (fZDF). Their weight gain was comparable to that observed for age-matched male ZDF rats (mZDF), but blood glucose levels were higher in the males (Fig. 1A and B). At the
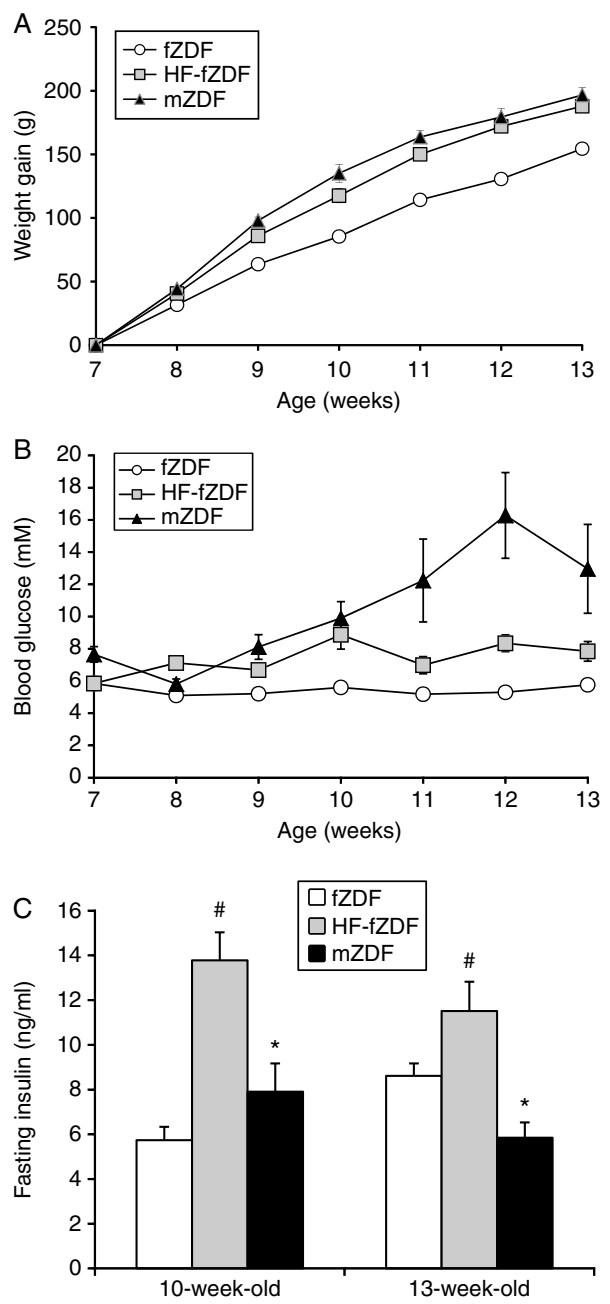

Figure 1 Effects of sex and high-fat diet on weight gain, glucose and insulin levels in ZDF rats. (A) Body weights and (B) blood glucose levels were weekly determined in $2 \mathrm{~h}$ fasted rats. (C) Serum levels of insulin were determined in $10 \mathrm{~h}$ fasted 10- and 13-week-old animals. $\left(^{*}\right)$ Indicate significant difference between fZDF and mZDF, (\#) indicate significant difference between fZDF and HF-fZDF $(P<0.05, n=5)$. 
A
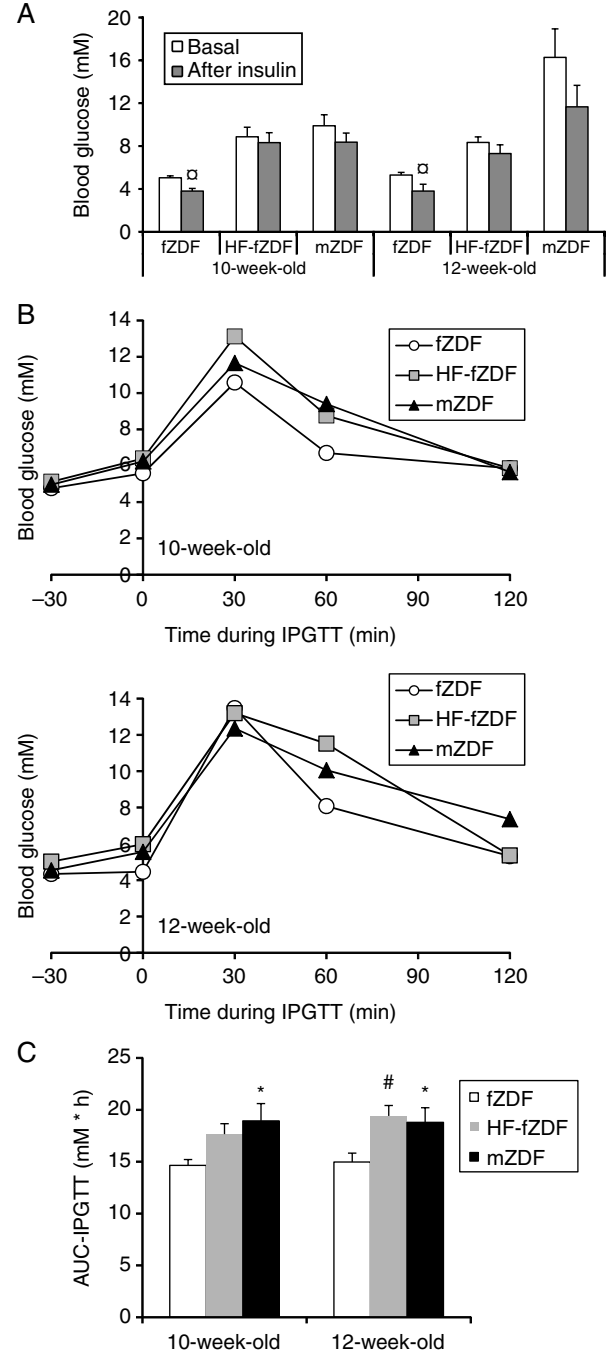

Figure 2 Effects of sex and high-fat diet on insulin sensitivity and glucose tolerance in ZDF rats. (A) Blood glucose levels were determined in $2 \mathrm{~h}$ fasted rats from a drop of blood from the tail before and $40 \mathrm{~min}$ after s.c. injection with insulin $(1 \mathrm{mU} / \mathrm{g}$ body weight). (a) Indicate significant effect of insulin $(P<0.05, n=5)$, as determined by paired, two-tailed Student's $t$-test. (B) Intraperitoneal glucose tolerance (IPGTT) tests were performed in $10 \mathrm{~h}$ fasted rats upon i.p. injections with $1 \mathrm{~g}$ glucose $/ \mathrm{kg}$ body weight. (C) The IPGTT test was statistically determined by performing area under the curve (AUC) analysis. $\left(^{*}\right)$ Indicate significant difference between $\mathrm{ZDF}$ and $\mathrm{mZDF},(\#)$ indicates significant difference between fZDF and HF-fZDF $(P<0 \cdot 05, n=5)$.

end of the study (6 weeks on high-fat diet), HF-fZDF had higher $10 \mathrm{~h}$ fasted serum insulin levels, whereas mZDF had lower insulin levels, compared with fZDF (Fig. 1C). Insulin sensitivity and glucose tolerance in 10and 12-week-old rats (3 and 5 weeks on high-fat diet) are shown in Fig. 2. HF-fZDF showed reduced insulin responses at both time points, similar to those recorded for mZDF. Only fZDF showed significant insulin-mediated effects on blood glucose levels (Fig. 2A). After an IPGTT, glucose levels of HF-fZDF and mZDF increased to a greater extent when compared with fZDF (Fig. 2B and C). Taken together, this confirms previous reports on a sex-different development of T2D in this animal model (Clark $e t$ al. 1983, Corsetti et al. 2000), and suggests that 5 weeks of high-fat feeding in fZDF leads to a prediabetic state with enhanced weight gain, increased blood glucose and insulin levels, reduced insulin sensitivity and reduced glucose tolerance. Reduced insulin levels in 13-weekold mZDF have been described before (Orci et al. 1990) and is indicative of diabetes development in the males.

In experimental models of obesity and T2D, JNK is activated (phosphorylated) in the liver by oxidants and cytokines and mediates obesity-induced insulin resistance (Hirosumi et al. 2002). As demonstrated in Fig. 3, only mZDF had increased levels of activated JNK, indicative of increased hepatic oxidative stress in this group of rats.

Whole-genome microarrays were used to identify high-fat diet-induced changes in hepatic gene expression, comparing 13-week-old fZDF and HF-fZDF animals (groups 4 and 5 , as described in Table 1). Out of 27649 genes printed on the arrays, $\sim 3500$ were detected in liver. Using a $5 \%$ FDR and a cutoff at $1 \cdot 5$ fold difference, 94 transcripts were identified as being differentially expressed between the groups (Supplementary Table 1, see section on supplementary data given at the end of this article). Functional annotation of the differentiated transcripts revealed that females developing insulin resistance and glucose intolerance

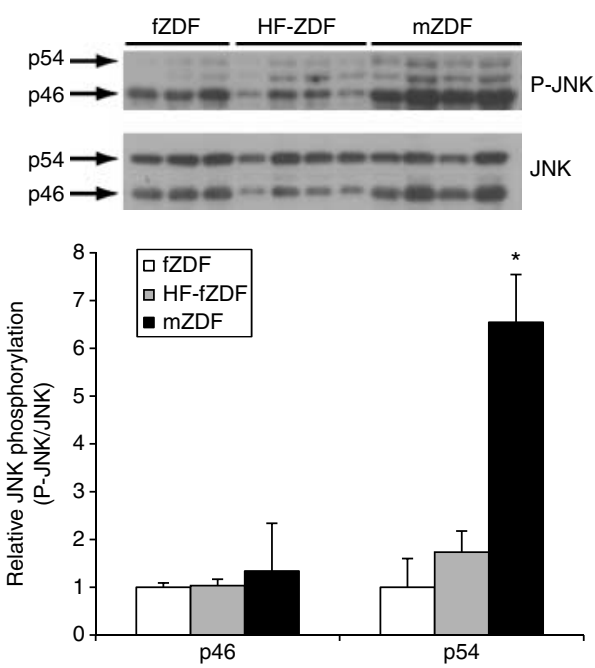

Figure 3 Effects of sex and high-fat diet on hepatic JNK phosphorylation in ZDF rats. The ratio between phosphorylated and unphosphorylated JNK was determined in whole liver cell lysates using immunoblotting. Data are represented as relative degrees of phosphorylation. $\left(^{*}\right)$ Indicates significant difference between fZDF and mZDF. 
have increased levels of gene products for FA oxidation (dodecenoyl-CoA delta isomerase, carnitine palmitoyltransferase 1 (CPT-1a), 3-hydroxy-3-methylglutaryl-CoA synthase 2 and 2,4-dienoyl-CoA reductase 2) and reduced levels of transcripts for de novo lipid synthesis (ELOVL family member 6, malic enzyme 1, stearoylCoA desaturase 1,7-dehydrocholesterol reductase, 3-hydroxy-3-methylglutaryl-CoA reductase, 3-hydroxy-3methylglutaryl-CoA synthase 1, acetyl-CoA synthetase 2, glycerol-3-phosphate acyltransferase, acetyl-CoA carboxylase $\beta$ (ACC $\beta)$, ATP-citrate synthase, and ATPcitrate lyase). Signs of increased oxidative stress included elevated levels of metallothionein $(M t 1)$ and angiotensinogen mRNA.

To find sex-dependent hepatic gene products that might be related to disease development, transcript profiling was performed comparing 13-week-old fZDF and mZDF animals (groups 4 and 6 , as described in Table 1). This resulted in 168 differentially expressed hepatic transcripts, being either male- or femalepredominant (Supplementary Table 1, see section on supplementary data given at the end of this article). Interestingly, among the 94 diet-induced changes described above, 33 were sex-dependent (Fig. 4A). Furthermore, when data values derived from the microarrays were graphically represented in a heat map, the overall pattern of sex-dependent gene expression was similar to the effects of the diabetogenic diet in fZDF (Fig. 4B). Female-predominant transcripts (represented in blue) were mainly down-regulated in response to high-fat feeding (represented in blue), whereas male-predominant transcripts (represented in red) were mostly up-regulated in response to high-fat feeding (represented in red). When Ingenuity Pathways Analysis was performed by all significant gene products, cellular functions including the metabolism of pyruvate, lipids, steroids and drugs, as well as oxidative stress, were identified as being similarly affected by diet and sex (Table 3). The overlapping effects at individual gene expression levels are summarised in Table 4 (excluding gene products lacking annotation), including several gene products for lipid synthesis (femalepredominant and reduced by high-fat diet), FA oxidation and oxidative stress (male-predominant and induced by high-fat diet).

Ten gene products with differential expression and important functions in hepatic lipid metabolism or metabolic stress responses were selected for validation through real-time quantitative PCR. The results are summarised in Fig. 5. Expression of CPT-1a, Mt1 and phosphoenolpyruvate carboxykinase 1 (PEPCK) were confirmed to be male-predominant and (except for PEPCK) induced by high-fat feeding in females. Insulin-induced gene 1 (Insig-1), ACC $\alpha$, Pnpla3, glutathione $S$-transferase Ya (GSTa1), glutathione S-transferase m2 (GSTm2), betaine-homocysteine
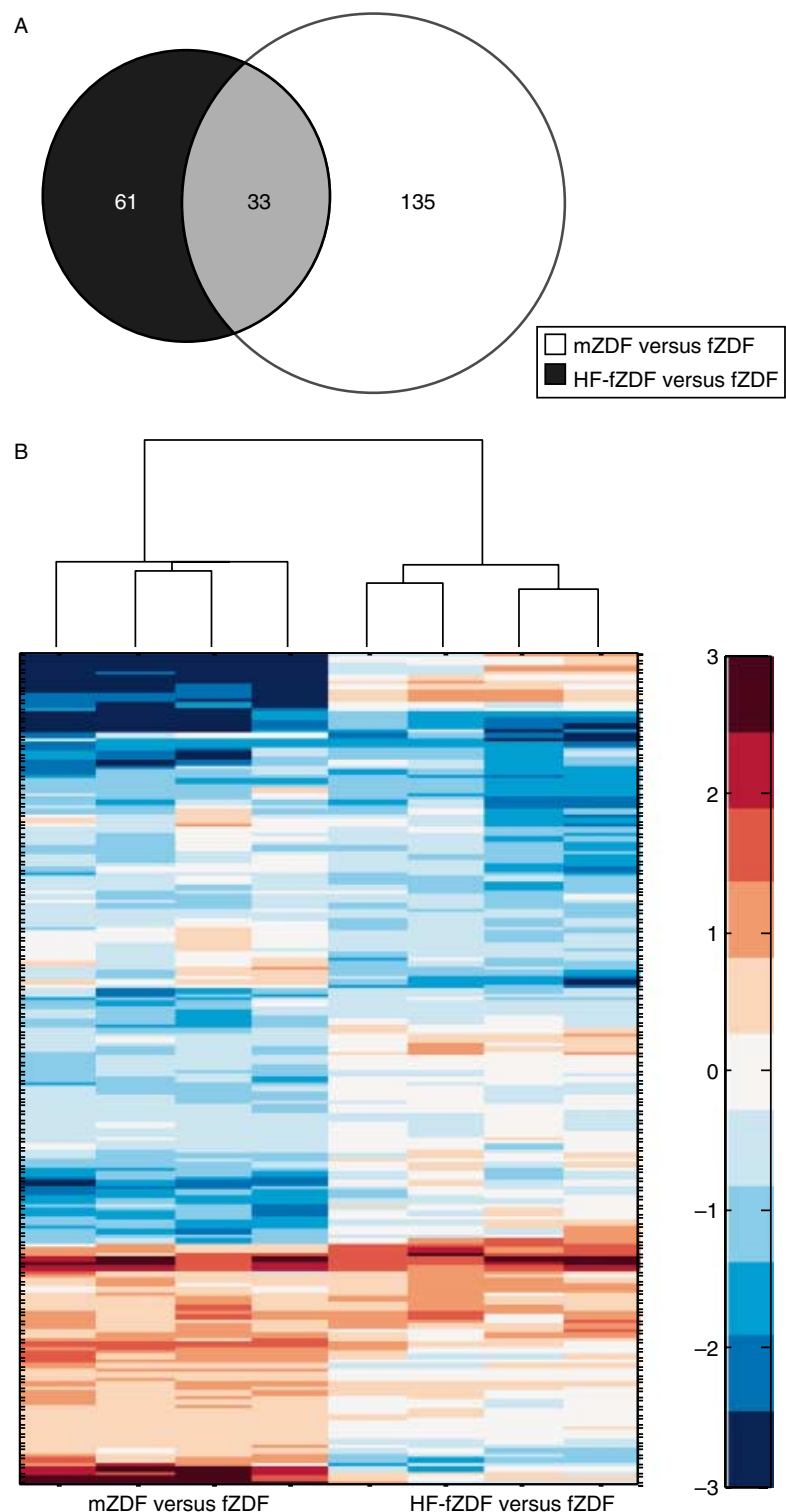

Figure 4 Effects of sex and/or high-fat diet on hepatic mRNA expression in ZDF rats. Total hepatic RNA was extracted from fZDF, HF-fZDF and mZDF rats ( $n=4$ per group) and effects of sex and high-fat feeding on mRNA expression levels were determined by whole-genome array analysis. The figure represents an overview of the results presented either $(A)$ as the number of significant transcripts with at least 1.5-fold differences between the groups or $(B)$ in a heat map reflecting ratios for all significantly different transcripts.

methyltransferase $(B h m t)$ and $\mathrm{NAD}(\mathrm{P}) \mathrm{H}$ dehydrogenase, quinone 1 (NQO1) were confirmed to be female-predominant (except for $B h m t$ ) and reduced by high-fat feeding (except for $A C C \alpha$ and NQO1). The largest effects were observed for Pnpla3, a gene product recently shown to be involved in the development of hepatic steatosis. As illustrated in Fig. 6, PNPLA3 
Table 3 Top ten canonical pathways and tox lists from Ingenuity Pathways Analysis using hepatic transcripts affected by high-fat feeding and/or sex in Zucker diabetic fatty (ZDF) rats

HF-fZDF versus fZDF

Canonical pathways

Tox lists

\author{
Pyruvate metabolism \\ LPS/IL1 mediated inhibition of RXR function \\ Biosynthesis of steroids \\ Propanoate metabolism \\ PXR/RXR activation \\ Fatty acid metabolism \\ Selenoamino acid metabolism \\ Arachidonic acid metabolism \\ Tyrosine metabolism \\ Glycolysis/gluconeogenesis \\ Cholesterol biosynthesis \\ LPS/IL1 mediated inhibition of RXR function \\ PXR/RXR activation \\ NRF2-mediated oxidative stress response \\ Xenobiotic metabolism signalling \\ Fatty acid metabolism \\ Glutathione depletion - phase II reactions \\ $\mathrm{LXR} / \mathrm{RXR}$ activation \\ Oxidative stress \\ Cardiac necrosis/cell death
}

mZDF versus fZDF

\author{
Fatty acid metabolism \\ LPS/IL1 mediated inhibition of RXR function \\ Pyruvate metabolism \\ Linoleic acid metabolism \\ Metabolism of xenobiotics by cytochrome P450 \\ Arachidonic acid metabolism \\ Tryptophan metabolism \\ Biosynthesis of steroids \\ Androgen and oestrogen metabolism \\ Propanoate metabolism
}

LPS/IL1 mediated inhibition of RXR function

Cytochrome P450 panel - substrate is a xenobiotic (rat)

Xenobiotic metabolism signalling

Cholesterol biosynthesis

NRF2-mediated oxidative stress response

Cytochrome P450 panel - substrate is a xenobiotic (mouse)

CAR/RXR activation

PXR/RXR activation

Cytochrome P450 panel - substrate is a fatty acid (rat)

Cytochrome P450 panel - substrate is a fatty acid (mouse) protein was down-regulated in HF-fZDF and mZDF compared with $\mathrm{FZDF}$, suggesting that this gene product might be reduced in the liver during T2D development.

To evaluate if the overlapping set of differentially expressed genes could be related to liver-derived metabolites that differentiate male and fZDF rats regarding their susceptibility to develop diabetes, metabolite profiling on liver lysates was performed. A method based on CE-TOFMS was used, enabling separation and quantification of low molecular weight hydrophilic compounds such as amino acids and carbohydrates. As summarised in Supplementary Table 2, see section on supplementary data given at the end of this article, among 151 metabolites being detected in liver extracts, 57 were found to be significantly different between HF-fZDF and fZDF, whereas 51 were different between $\mathrm{mZDF}$ and $\mathrm{fZDF}$ (using a 5\% FDR and a cutoff at 1.2-fold difference). The biggest diet-mediated effect was observed for sarcosine, being reduced almost tenfold upon highfat feeding. Proline betaine, 4-guanidinobutyrate, trimethylamine $\mathrm{N}$-oxide, glutathione (GSH), $\mathrm{N}, \mathrm{N}-$ dimethylglycine and 6-phosphogluconate were also reduced (more than twofold), whereas 2-aminooctanoate, o-propionylcarnitine, glutamate, 2-aminobutyrate and carnitine were induced (more than twofold). Ophthalmate was also greatly induced (more than fivefold), but the effect did not reach significance $(P=0 \cdot 063)$. Taken together, these metabolic changes indicate increased activity through catabolic pathways (FA oxidation and amino acid degradation) and reduced biosynthesis of GSH and its precursors within the livers of HF-fZDF.

Among the 57 high-fat diet-mediated changes in liver-derived metabolites described earlier, 25 were sexdependent (Fig. 7 and Supplementary Table 2, see section on supplementary data given at the end of this article). As illustrated in Fig. 7B, seven clusters of significantly regulated metabolites were observed. The largest cluster consisted of female-predominant metabolites being reduced upon high-fat feeding, including metabolites from the glycolytic pathway and TCA cycle (pyruvate and malate), the pentose phosphate pathway (6-phosphogluconate and sedoheptulose 7-phosphate), as well as some metabolites related to GSH synthesis (sarcosine, N,N-dimethylglycine and cystathionine). Ophthalmate, an analogue of GSH, was higher in females. GSH itself was not significantly different between fZDF and mZDF rats, but a trend towards higher levels in females was observed $(1 \cdot 25$-fold, $P=0 \cdot 176)$.

\section{Discussion}

mZDF rats spontaneously develop insulin resistance, hyperglycaemia and diabetes, whereas females only become diabetic when fed a diabetogenic high-fat diet (Corsetti et al. 2000). This indicates that fZDF rats are protected against T2D development and that this protection is diminished in females fed this diet. The exact reason why this particular diet is diabetogenic in 
Table 4 Hepatic transcripts affected by high-fat feeding and sex in Zucker diabetic fatty (ZDF) rats. The table represents relative levels of hepatic transcripts, comparing either female ZDF rats on high-fat diet (HF-fZDF) versus female ZDF (fZDF) rats on standard diet, or male ZDF (mZDF) rats versus fZDF rats (on standard diet). Hepatic RNA was extracted from the rats $(n=4)$ and the effect on mRNA expression was determined by whole-genome arrays. Transcripts showing at least 1.5 -fold differences with a false discovery rate $<5 \%$ were considered to be differentially expressed. The data are presented as ratios between the indicated groups, including only the high-fat dietaffected transcripts with a sex-dependent level

Ratio

Ref seq

Lipid turnover (fatty acid oxidation)

NM_017306

NM_031559

NM_173094

NM 171996

NM_175760

Various

NM_138826

NM_145084

NM_134432

NM_012744

NM 017025

Lipid turnover (lipogenesis)

NM 134383

NM_022392

NM 012600

XM_230773

NM_017274

NM 053922

Various

XM 342121.1

NM_001010921

XM 343302

XM_235538

XM 344275

NM_022268

NM_057137

XM_342979.2

Gene
Dodecenoyl-Coenzyme A $\delta$ isomerase $(D c l)$

Carnitine palmitoyltransferase 1 (CPT-1a)

3-Hydroxy-3-methylglutaryl-Coenzyme A synthase 2 (HMGCS2)

2,4-Dienoyl-CoA reductase 2, peroxisomal (DECR2)

Cytochrome P450, family 4, subfamily a, polypeptide 3 (Cyp4a3)

Metallothionein $(M t 1)$

All-trans-13,14-dihydroretinol saturase (RetSat)

Angiotensinogen $(A g t)$

Pyruvate carboxylase $(P C)$

Lactate dehydrogenase $\mathrm{A}(L d h A)$

ELOVL family member 6, elongation of long-chain fatty acids (Elovl6)

Insulin-induced gene 1 (Insig-1)

Malic enzyme 1 (Me1)

Acetyl-Coenzyme A synthetase 2 (Acas2)

Glycerol-3-phosphate acyltransferase, mitochondrial (Gpam)

Acetyl-Coenzyme A carboxylase $\beta(A C C \beta)$

Glutathione S-transferase, theta 3 (GSTt3)

Glutathione S-transferase Ya (GSTa1)

Patatin-like phospholipase domain containing 3 (adiponutrin, Pnpla3)

Patatin-like phospholipase domain containing 5 (Pnpla5)

Acylphosphatase 2 (Acyp2)

Liver glycogen phosphorylase (PYGL)

Phenylalkylamine $\mathrm{Ca}^{2+}$ antagonist (emopamil) binding protein (Ebp)

Phosphogluconate dehydrogenase (predicted, Pgd)

\begin{tabular}{ll}
\hline $\begin{array}{ll}\text { HF-fZDF } \\
\text { versus fZDF }\end{array}$ & mZDF \\
&
\end{tabular}

$4 \cdot 20 \quad 2 \cdot 29$

$3.14 \quad 1.73$

$1.82 \quad 1.60$

$1 \cdot 81 \quad 2 \cdot 04$

$1.55 \quad 2 \cdot 11$

$3.82 \quad 4.56$

$2 \cdot 21 \quad 2 \cdot 06$

$1 \cdot 85 \quad 1 \cdot 81$

$1 \cdot 72 \quad 1.65$

$1.65 \quad 1.57$

$0.28 \quad 0.29$

$0.34 \quad 0.44$

$0.35 \quad 0.50$

$0.39 \quad 0.47$

$0.42 \quad 0.37$

$0.46 \quad 0.33$

$0.22 \quad 0.36$

$0.51 \quad 0.60$

$0.28 \quad 0.13$

$0.34 \quad 0.13$

$0.45 \quad 0.61$

$0.64 \quad 0.59$

$0.54 \quad 0.58$

$0.49 \quad 0.31$ this animal model is not known, but it is higher in fat and lower in protein and carbohydrates compared with standard chow. The aim of this study was to test the hypothesis that $\mathrm{fZDF}$ rats put on this high-fat diabetogenic diet would develop a more male-like hepatic phenotype, including increased FA oxidation and ROS production, reduced lipogenesis and/or increased gluconeogenesis. Molecular profiles were generated from liver extracts to compare the picture of diet-induced metabolic alterations with that of sex-dependent differences, and to find hepatic parameters that might protect $\mathrm{fZDF}$ rats from developing diabetes.

By identifying high-fat diet-induced changes in hepatic gene expression, a picture of reduced hepatic lipogenesis and increased FA oxidation and metabolic stress appeared that might be related to disease development. A similar picture was observed at the level of liver-derived metabolites. Among the high-fat feeding-induced changes in fZDF rats, $\sim 35 \%$ of the transcripts and $65 \%$ of the metabolites were altered towards a 'male-like' phenotype. This could be interpreted as if anabolic pathways protect $\mathrm{fZDF}$ livers from developing insulin resistance. On the other hand, these disease-related changes in transcripts and metabolites might only be a consequence of reduced insulin sensitivity and/or hyperglycaemia. However, the sex differences observed in this study are similar to those described in healthy rats, with $50 \%$ of the sexdependent genes from this study being similar to those observed in SD rats (Gustavsson et al. 2010). These include gene products such as glycerol-3phosphate acyltransferase and acetyl-coenzyme A synthetase 2 (being female-predominant and reduced upon high-fat feeding) and lactate dehydrogenase A and CPT-1a (being male-predominant and induced upon high-fat feeding).

Several of our findings have already been described by others and confirm the notion that $\mathrm{ZZDF}$ rats are less susceptible to diabetes development (Clark et al. 1983, Corsetti et al. 2000). Four weeks of high-fat 

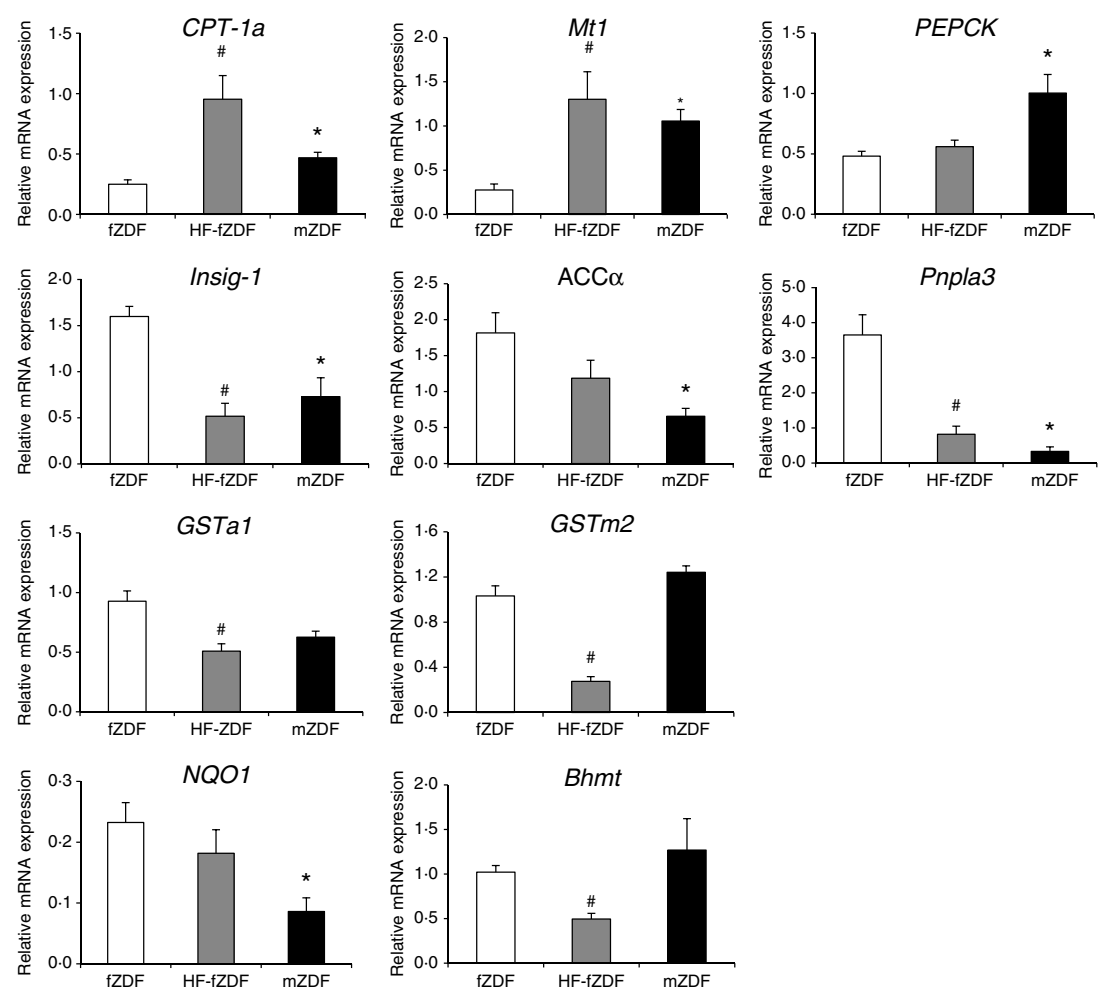

Figure 5 Effects of sex and/or high-fat diet on selected hepatic transcripts in ZDF rats. Total hepatic RNA was extracted from fZDF, HF-fZDF and mZDF rats and the effects of sex and fat feeding on mRNA expression determined by real-time PCR. Selected transcripts and the corresponding primers used are listed in Table 2. Each measurement was correlated with the housekeeping gene Arbp to obtain relative mRNA expression levels. $\left(^{*}\right)$ Indicate significant difference between fZDF and mZDF, (\#) indicate significant difference between fZDF and HF-fZDF.

(48\% kcal fat) feeding will induce the development of marked hyperglycaemia in $\mathrm{FZDF}$, which leads to islet dysfunction and diabetes within the following 4 months (Corsetti et al. 2000). Interestingly, Corsetti et al. demonstrated that serum insulin levels were reduced in 22-weak-old HF-fZDF, in parallel with reduced levels of circulating lipids (total cholesterol and TG) and decreased number of TG-rich lipoprotein particles. The concentrations were comparable to those determined in mZDF of similar age (Corsetti et al. 2000). One explanation for this could be reduced hepatic lipogenesis and/or assembly of VLDL particles during diabetes development in the females. This might involve lipogenic gene products identified in this study, as being female-predominant and reduced upon high-fat feeding. Some male-predominant gene products were induced upon high-fat feeding in females, indicative of increased FA oxidation during diabetes development. Calorie restriction has been shown to prevent the development of diabetes in mZDF (Colombo et al. 2006). Interestingly, hepatic mRNA expression of key enzymes involved in lipid synthesis was up-regulated, whereas genes for FA oxidation were down-regulated in parallel with improved insulin sensitivity.

We speculate that a more efficient incorporation of hepatic FA into TG and VLDL particles and secretion of TG-enriched lipoprotein particles might contribute to a reduced hepatocellular load of lipids in obese females (fZDF). This and other lipid-clearing systems within the liver are likely to be saturated in HF-fZDF and mZDF animals, leading to elevated levels of FFA. This might in turn activate PPAR $\alpha$-dependent genes and hepatic FA oxidation, as well as reduce the actions through SREBPdependent lipogenic pathways. Results obtained in this study are in line with this and could be exemplified by higher expression levels of genes for FA oxidation in HF-fZDF and mZDF, compared with fZDF. Higher FA oxidation rates are known to increase the hepatocellular levels of ROS and the risk of developing hepatic insulin resistance (Houstis et al. 2006). We did not determine hepatic insulin sensitivity, but the insulinregulated gene product Insig-1, a negative regulator of SREBP maturation and lipogenesis (Engelking et al. 2004), was less expressed in HF-fZDF and mZDF, 

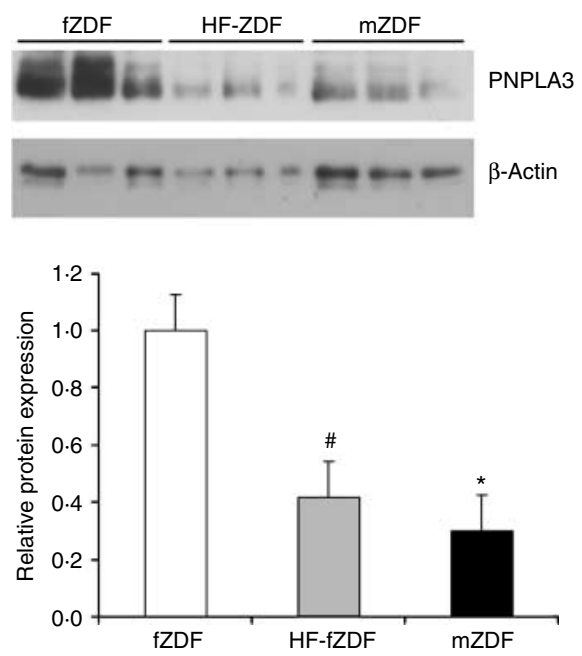

Figure 6 Effects of sex and/or high-fat diet on hepatic PNPLA3. Protein levels of PNPLA3 were analysed in whole liver cell lysates using immunoblotting and quantified by densitometry analysis in relation to $\beta$-actin (lower section). ( $\left.{ }^{*}\right)$ Indicates significant difference between $Z Z D F$ and $\mathrm{mZDF}$, (\#) indicates significant difference between fZDF and HF-fZDF.

compared with fZDF. Interestingly, hepatic Insig-1 or -2 overexpression has been shown to reduce lipogenesis in obese ZDF rats (Takaishi et al. 2004).

Various challenges such as high-fat feeding, toxins, viral infections or surgery-induced metabolic overload can induce the formation of ROS and electrophilic substances within the liver. To maintain a favourable redox balance (counteracting ROS), mammalian cells utilise an inducible cell defence system, 'the antioxidant response pathway'. In this way, the cell can respond to increased levels of ROS and adjust the production of GSH, GSH transferases (GST) and other phase II enzymes. This pathway can be exhausted if the cellular levels of GSH are insufficient, leading to insulin resistance and liver toxicity (Houstis et al. 2006). Earlier reports on increased levels of malondialdehyde (a lipid peroxidation product; Koneru et al. 1995) and reduced levels of GSH (Soltys et al. 2001, Serkova et al. 2006) in fatty livers of obese ZDF rats, support the notion of increased hepatic ROS production and GSH consumption in this model. In this study, indications of higher ROS production in HF-fZDF and mZDF included increased levels of $M t 1$ and angiotensinogen mRNA, two gene products known to be induced by various forms of oxidative stress. Surprisingly, gene products being induced by oxidative stress and involved in the antioxidant response (GSTa1, GSTm2 and NQO1) were reduced in HF-fZDF and/or mZDF animals. The reason for this is not known, but is likely to reduce hepatic detoxification capacity.
Hepatic angiotensinogen is part of the reninangiotensin-aldosterone system, which functions in the homeostatic control of arterial pressure, tissue perfusion and extracellular volume (Manrique et al. 2009). Using mZDF rats, angiotensinogen was recently shown to be induced in mesangial cells via ROS/ ERK/JNK pathways (Ohashi et al. 2010), and similar mechanisms might be operating in the liver. MT1 is a potent cellular antioxidant that plays important roles in essential trace element homeostasis, metal detoxification and in the protection against various injuries resulting from ROS (Chiaverini \& De Ley 2010), including the development of diabetes and its complications (Ohly et al. 2000, Cai 2004, Li et al. 2004, Song et al. 2005, Ayaz et al. 2006, Tang et al. 2010). It has also been shown that levels of MT1 are increased in the livers of diabetic rats (Cai et al. 2002), which is in agreement with the results obtained in this study. Mt1 mRNA levels showed the greatest sex difference among the gene products being confirmed as male-predominant and induced by high-fat feeding, together with angiotensinogen and genes involved in FA oxidation.

Among the gene products being confirmed to be female-predominant and reduced by high-fat feeding, Pnpla3 showed the greatest sex difference. PNPLA3 is a predominantly liver-expressed transmembrane protein with lipase activity that is regulated by fasting and feeding. Although its putative role in metabolic disease development has only recently started to be explored, various genome-wide association studies have identified the Pnpla3 gene to be associated with liver-related phenotypes (Romeo et al. 2008, Yuan et al. 2008, Kotronen et al. 2009). Since it is up-regulated in response to feeding and downregulated in the fasted state, a potential role for Pnpla 3 in lipid storage has been suggested (Baulande et al. 2001, Lake et al. 2005, Moldes et al. 2006, Wilson et al. 2006). Furthermore, the transcription factors SREBPs, PPAR $\gamma$ and ChREBP have been shown to mediate increased expression of the Pnpla3 gene (Baulande et al. 2001, Polson \& Thompson 2003). This is in line with results presented in this study, where Pnpla3 was found to be co-regulated with genes of importance for de novo lipid synthesis. Interestingly, a recent study provides genetic evidence for a role of PNPLA3 in the metabolism of apolipoprotein B-containing lipoproteins (Kollerits et al. 2009). It might be speculated that reduced levels of PNPLA3 in HF-fZDF and mZDF affect packaging of these lipoproteins in the liver.

In addition to the diet-induced changes in hepatic mRNA expression, alterations were also detected at the level of hepatic metabolites. Livers from HF-fZDF had 2.5 times lower levels of GSH compared with fZDF, indicating a greater usage of GSH due to increased 
A
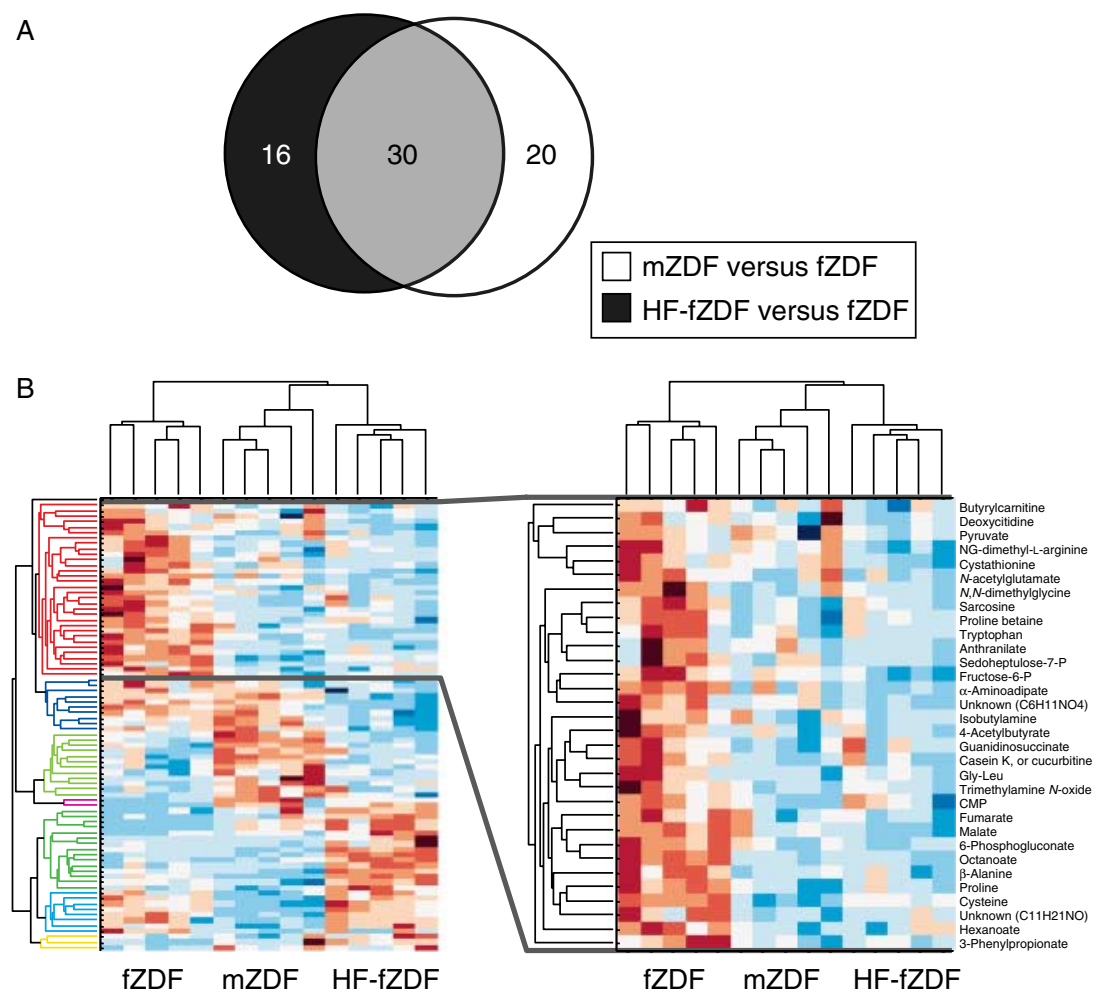

Figure 7 Effects of sex and/or high-fat diet on hepatic metabolites in ZDF rats. Hepatic metabolites were extracted from fZDF, HF-fZDF and mZDF rats ( $n=5$ per group) and effects of sex and high-fat feeding on metabolite levels were determined using CE-TOFMS. Metabolites showing at least 1-2-fold differences in concentration between the groups and with $P<0.05$ were considered significantly different. The figure represents an overview of the results presented either $(A)$ as the number of significant metabolites comparing the indicated groups or $(B)$ in a heat map reflecting levels of these metabolites in the different groups.

oxidative stress. Although mZDF and fZDF rats had almost similar GSH levels, many GSH-related metabolites or substrates (2-aminobutyrate, glycine, hypotaurine and serine) were lower in mZDF compared with fZDF. Furthermore, major differences in ophthalmate levels were observed, with $5 \cdot 8$-fold higher levels in HF-fZDF, whereas mZDF had $2 \cdot 0$ times lower levels (compared with fZDF).

We have previously shown that ophthalmate ( $\gamma$-Glu-2-aminobutyrate-Gly) is synthesised through the same pathway as GSH (Soga et al. 2006). Ophthalmate is synthesised from 2-aminobutyrate through $\gamma$-glutamylcysteine synthetase (GCS) and GSH synthetase. GCS is the rate-limiting enzyme and feedbackinhibited by GSH, and thus GSH consumption leads to GCS activation, resulting in enhanced biosynthesis of ophthalmate. Since ophthalmate levels were shown to predict the amount of GSH production (Soga et al. 2006), ophthalmate measurements provide valuable information about hepatic GSH turnover. In this study, GSH levels were reduced in HF-fZDF, while both ophthalmate and its substrate 2-aminobutyrate were increased. This suggests that although high-fat feeding in fZDF rats generates oxidative stress, the capacity to synthesise GSH might still be high due to sufficient amount of substrates (Cys, Glu, Gly, Ser, etc.). GSH can also be regenerated from GSSG using NADPH produced in the pentose phosphate pathway. Reduced levels of metabolites from the pentose phosphate pathway were observed in HF-fZD as well as in mZDF, which might be linked to a reduced capacity to regenerate GSH from GSSG in these animals, compared with fZDF. Nevertheless, these results indicate that both the capacity of GSH production and turnover were higher in female rats, which is in line with the finding that HF-fZDF had lower degree of phosphorylated JNK, compared with mZDF. Taken together, data presented in this study could be interpreted as if anabolic pathways involving lipogenesis and lipid output, might limit the degree FA oxidation and oxidative stress in female rats. Together with a greater capacity to produce GSH, these hepatic sex differences might contribute to the sex-different development of diabetes in ZDF rats. 


\section{Supplementary data}

This is linked to the online version of the paper at http://dx.doi.org/ 10.1530/JME-11-0007.

\section{Declaration of interest}

The authors declare that there is no conflict of interest that could be perceived as prejudicing the impartiality of the research reported.

\section{Funding}

This work was supported by grants from the Swedish Medical Research Council and the Swedish Society of Medical Research.

\section{Acknowledgements}

We are grateful to Naoko Toki and Ayako Momose (Keio University, Japan) for technical support and Peter Nilsson (KTH Royal Institute of Technology, Sweden) for the kind gift of the microarrays.

\section{References}

Arenas IA, Armstrong SJ, Xu Y \& Davidge ST 2005 Chronic tumor necrosis factor- $\alpha$ inhibition enhances NO modulation of vascular function in estrogen-deficient rats. Hypertension 46 76-81. (doi:10. 1161/01.HYP.0000168925.98963.ef)

Ayaz M, Celik H, Aydin H \& Turan B 2006 Sodium selenite protects against diabetes-induced alterations in the antioxidant defense system of the liver. Diabetes/Metabolism Research and Reviews 22 295-299. (doi:10.1002/dmrr.601)

Baba T, Shimizu T, Suzuki Y, Ogawara M, Isono K, Koseki H, Kuosawa H \& Shirasawa T 2005 Estrogen, insulin and dietary signals cooperatively regulate longevity signals to enhance resistance to oxidative stress in mice. Journal of Biological Chemistry 280 16417-16426. (doi:10.1074/jbc.M500924200)

Baulande S, Lasnier F, Lucas M \& Pairault J 2001 Adiponutrin, a transmembrane protein corresponding to a novel dietary- and obesity-linked mRNA specifically expressed in the adipose lineage. Journal of Biological Chemistry 276 33336-33344. (doi:10.1074/jbc. M105193200)

Borrás C, Gambini J, Gómez-Cabrera MC, Sastre J, Pallardó FV, Mann GE \& Viña J 2005 17ß-Oestradiol up-regulates longevity-related, antioxidant enzyme expression via the ERK1 and ERK2[MAPK] NFкB cascade. Aging Cell 4 113-118. (doi:10.1111/j.1474-9726.2005. 00151.x)

Bryzgalova G, Gao H, Ahren B, Zierath JR, Galuska D, Steiler TL, Dahlman-Wright K, Nilsson S, Gustafsson JÃ, Efendic S et al. 2006 Evidence that oestrogen receptor- $\alpha$ plays an important role in the regulation of glucose homeostasis in mice: insulin sensitivity in the liver. Diabetologia 49 588-597. (doi:10.1007/ s00125-005-0105-3)

Cai L 2004 Metallothionein as an adaptive protein prevents diabetes and its toxicity. Nonlinearity in Biology, Toxicology and Medicine 2 89-103. (doi:10.1080/15401420490464367)

Cai L, Chen S, Evans T, Cherian M \& Chakrabarti S 2002 Endothelin-1mediated alteration of metallothionein and trace metals in the liver and kidneys of chronically diabetic rats. International Journal of Experimental Diabetes Research 3 193-198. (doi:10.1080/ 15604280214281 )
Cheung O \& Sanyal A 2010 Recent advances in nonalcoholic fatty liver disease. Current Opinion in Gastroenterology 26 202-208. (doi:10. 1097/MOG.0b013e328337b0c4)

Chiaverini N \& De Ley M 2010 Protective effect of metallothionein on oxidative stress-induced DNA damage. Free Radical Research 44 605-613. (doi:10.3109/10715761003692511)

Clark J, Palmer C \& Shaw W 1983 The diabetic Zucker fatty rat. Proceedings of the Society for Experimental Biology and Medicine $\mathbf{1 7 3}$ $68-75$.

Colombo M, Kruhoeffer M, Gregersen S, Agger A, Jeppesen P, Oerntoft T \& Hermansen K 2006 Energy restriction prevents the development of type 2 diabetes in Zucker diabetic fatty rats: coordinated patterns of gene expression for energy metabolism in insulin-sensitive tissues and pancreatic islets determined by oligonucleotide microarray analysis. Metabolism: Clinical and Experimental 55 43-52. (doi:10.1016/j.metabol.2005. 07.005)

Corsetti JP, Sparks JD, Peterson RG, Smith RL \& Sparks CE 2000 Effect of dietary fat on the development of non-insulin dependent diabetes mellitus in obese Zucker diabetic fatty male and female rats. Atherosclerosis 148 231-241. (doi:10.1016/S00219150(99)00265-8)

D'Eon TM, Souza SC, Aronovitz M, Obin MS, Fried SK \& Greenberg AS 2005 Estrogen regulation of adiposity and fuel partitioning. Journal of Biological Chemistry 280 35983-35991. (doi:10.1074/jbc. M507339200)

Engelking LJ, Kuriyama H, Hammer RE, Horton JD, Brown MS, Goldstein JL \& Liang G 2004 Overexpression of Insig-1 in the livers of transgenic mice inhibits SREBP processing and reduces insulinstimulated lipogenesis. Journal of Clinical Investigation 113 1168-1175. (doi:10.1172/JCI20978)

Gustavsson C, Parini P, Ostojic J, Cheung L, Hu J, Zadjali F, Tahir F, Brismar K, Norstedt G \& Tollet-Egnell P 2009 Cocoa butter and safflower oil elicit different effects on hepatic gene expression and lipid metabolism in rats. Lipids 44 1011-1027. (doi:10.1007/s11745009-3352-0)

Gustavsson C, Yassin K, Wahlström E, Cheung L, Lindberg J, Brismar K, Östenson C-G, Norstedt G \& Tollet-Egnell P 2010 Sex-different hepatic glycogen content and glucose output in rats. $B M C$ Biochemistry 23 38. (doi:10.1186/1471-2091-11-38)

Hawkins J, Jones W, Bonner F \& Gibson G 1987 The effect of peroxisome proliferators on microsomal, peroxisomal, and mitochondrial enzyme activities in the liver and kidney. Drug Metabolism Reviews 18 441-515. (doi:10.3109/0360253870 8994130)

Hirosumi J, Tuncman G, Chang L, Gorgun CZ, Uysal KT, Maeda K, Karin M \& Hotamisligil GS 2002 A central role for JNK in obesity and insulin resistance. Nature 420 333-336. (doi:10.1038/ nature01137)

Horton TJ, Gayles EC, Prach PA, Koppenhafer TA \& Pagliassotti MJ 1997 Female rats do not develop sucrose-induced insulin resistance. American Journal of Physiology. Regulatory, Integrative and Comparative Physiology 272 R1571-R1576.

Houstis N, Rosen ED \& Lander ES 2006 Reactive oxygen species have a causal role in multiple forms of insulin resistance. Nature $\mathbf{4 4 0}$ 944-948. (doi:10.1038/nature04634)

Isomaa B, Almgren P, Tuomi T, Forsen B, Lahti K, Nissen M, Taskinen M-R \& Groop L 2001 Cardiovascular morbidity and mortality associated with the metabolic syndrome. Diabetes Care 24 683-689. (doi:10.2337/diacare.24.4.683)

Kawashima Y, Uy-Yu N \& Kozuka H $1989 a$ Sex-related difference in the inductions by perfluoro-octanoic acid of peroxisomal betaoxidation, microsomal 1-acylglycerophosphocholine acyltransferase and cytosolic long-chain acyl-CoA hydrolase in rat liver. Biochemical Journal 261 595-600.

Kawashima Y, Uy-Yu N \& Kozuka H $1989 b$ Sex-related differences in the enhancing effects of perfluoro-octanoic acid on stearoyl-CoA 
desaturase and its influence on the acyl composition of phospholipid in rat liver. Comparison with clofibric acid and tiadenol. Biochemical Journal 263 897-904.

Kim HJ, Kim HJ, Lee KE, Kim DJ, Kim SK, Ahn CW, Lim S-K, Kim KR, Lee HC, Huh KB et al. 2004 Metabolic significance of nonalcoholic fatty liver disease in nonobese, nondiabetic adults. Archives of Internal Medicine 164 2169-2175. (doi:10.1001/archinte.164.19. 2169)

Kim S, Min W-K, Chun S, Lee W, Chung H-J, Lee PR \& Kim A 2009 Quantitative risk estimation for large for gestational age using the area under the 100 -g oral glucose tolerance test curve. Journal of Clinical Laboratory Analysis 23 231-236. (doi:10.1002/ jcla.20326)

Kollerits B, Coassin S, Beckmann ND, Teumer A, Kiechl S, Döring A, Kavousi M, Hunt SC, Lamina C, Paulweber B et al. 2009 Genetic evidence for a role of adiponutrin in the metabolism of apolipoprotein B-containing lipoproteins. Human Molecular Genetics 18 4669-4676. (doi:10.1093/hmg/ddp424)

Koneru B, Reddy M, dela Torre A, Patel D, Ippolito T \& Ferrante R 1995 Studies on hepatic warm ischemia in the obese Zucker rat. Transplantation 59 942-946. (doi:10.1097/00007890-19950415000003)

Kotronen A, Johansson L, Johansson L, Roos C, Westerbacka J, Hamsten A, Bergholm R, Arkkila P, Arola J, Kiviluoto T et al. 2009 A common variant in PNPLA3, which encodes adiponutrin, is associated with liver fat content in humans. Diabetologia $\mathbf{5 2}$ 10561060. (doi:10.1007/s00125-009-1285-z)

Kushlan MC, Gollan JL, Ma W-L \& Ockner RK 1981 Sex differences in hepatic uptake of long chain fatty acids in single-pass perfused rat liver. Journal of Lipid Research 22 431-436.

Lake AC, Sun Y, Li J-L, Kim JE, Johnson JW, Li D, Revett T, Shih HH, Liu W, Paulsen JE et al. 2005 Expression, regulation, and triglyceride hydrolase activity of Adiponutrin family members. Journal of Lipid Research 46 2477-2487. (doi:10.1194/jlr.M500290JLR200)

Legato MJ, Gelzer A, Goland R, Ebner SA, Rajan S, Villagra V \& Kosowski M 2006 Gender-specific care of the patient with diabetes: review and recommendations. Gender Medicine 3 131-158. (doi:10. 1016/S1550-8579(06)80202-0)

Li X, Chen H \& Epstein P 2004 Metallothionein protects islets from hypoxia and extends islet graft survival by scavenging most kinds of reactive oxygen species. Journal of Biological Chemistry 279 765-771. (doi:10.1074/jbc.M307907200)

Louet J, LeMay C \& Mauvais-Jarvis F 2004 Antidiabetic actions of estrogen: insight from human and genetic mouse models. Current Atherosclerosis Reports 6 180-185. (doi:10.1007/s11883-004-0030-9)

Manrique C, Lastra G, Gardner M \& Sowers JR 2009 The renin angiotensin aldosterone system in hypertension: roles of insulin resistance and oxidative stress. Medical Clinics of North America 93 569-582. (doi:10.1016/j.mcna.2009.02.014)

Moldes M, Beauregard G, Faraj M, Peretti N, Ducluzeau P-H, Laville M, Rabasa-Lhoret R, Vidal H \& Clement K 2006 Adiponutrin gene is regulated by insulin and glucose in human adipose tissue. European Journal of Endocrinology 155 461-468. (doi:10.1530/eje.1.02229)

Moran A, Jacobs DRJr, Steinberger J, Steffen LM, Pankow JS, Hong C-P \& Sinaiko AR 2008 Changes in insulin resistance and cardiovascular risk during adolescence: establishment of differential risk in males and females. Circulation 117 2361-2368. (doi:10.1161/CIRCULATIONAHA.107.704569)

Ohashi N, Urushihara M, Satou R \& Kobori H 2010 Glomerular angiotensinogen is induced in mesangial cells in diabetic rats via reactive oxygen species - ERK/JNK pathways. Hypertension Research 33 1174-1181. (doi:10.1038/hr.2010.143)

Ohly P, Dohle C, Abel J, Seissler J \& Gleichmann H 2000 Zinc sulphate induces metallothionein in pancreatic islets of mice and protects against diabetes induced by multiple low doses of streptozotocin. Diabetologia 43 1020-1030. (doi:10.1007/s001250050009)
Orci L, Ravazzola M, Baetens D, Inman L, Amherdt M, Peterson RG, Newgard CB, Johnson JH \& Unger RH 1990 Evidence that downregulation of beta-cell glucose transporters in non-insulin-dependent diabetes may be the cause of diabetic hyperglycemia. PNAS 87 9953-9957. (doi:10.1073/pnas.87.24.9953)

Perrone G, Liu Y, Capri O, Critelli C, Barillaro F, Galoppi P \& Zichella L 1999 Evaluation of the body composition and fat distribution in long-term users of hormone replacement therapy. Gynecologic and Obstetric Investigation 48 52-55. (doi:10.1159/000010134)

Polson D \& Thompson M 2003 Adiponutrin gene expression in 3T3-L1 adipocytes is downregulated by troglitazone. Hormone and Metabolic Research 35 508-510. (doi:10.1055/s-2003-41811)

Regitz-Zagrosek V, Lehmkuhl E \& Mahmoodzadeh S 2007 Gender aspects of the role of the metabolic syndrome as a risk factor for cardiovascular disease. Gender Medicine 4 S162-S177. (doi:10.1016/ S1550-8579(07) 80056-8)

Riant E, Waget A, Cogo H, Arnal J-F, Burcelin R \& Gourdy P 2009 Estrogens protect against high-fat diet-induced insulin resistance and glucose intolerance in mice. Endocrinology 150 2109-2117. (doi:10.1210/en.2008-0971)

Romeo S, Kozlitina J, Xing C, Pertsemlidis A, Cox D, Pennacchio LA, Boerwinkle E, Cohen JC \& Hobbs HH 2008 Genetic variation in PNPLA3 confers susceptibility to nonalcoholic fatty liver disease. Nature Genetics 40 1461-1465. (doi:10.1038/ng.257)

Serkova N, Jackman M, Brown J, Liu T, Hirose R, Roberts J, Maher J \& Niemann C 2006 Metabolic profiling of livers and blood from obese Zucker rats. Journal of Hepatology 44 956-962. (doi:10.1016/j.jhep. 2005.07.009)

Soga T \& Heiger DN 2000 Amino acid analysis by capillary electrophoresis electrospray ionization mass spectrometry. Analytical Chemistry 72 1236-1241. (doi:10.1021/ac990976y)

Soga T, Baran R, Suematsu M, Ueno Y, Ikeda S, Sakurakawa T, Kakazu Y, Ishikawa T, Robert M, Nishioka T et al. 2006 Differential metabolomics reveals ophthalmic acid as an oxidative stress biomarker indicating hepatic glutathione consumption. Journal of Biological Chemistry 281 16768-16776. (doi:10.1074/jbc.M601876200)

Soler-Argilaga C \& Heimberg M 1976 Comparison of metabolism of free fatty acid by isolated perfused livers from male and female rats. Journal of Lipid Research 17 605-615.

Soler-Argilaga C, Danon A, Goh E, Wilcox HG \& Heimberg M 1975 The effect of sex on the uptake of very low density lipoprotein triglyceride fatty acid from the plasma of the rat in vivo. Biochemical and Biophysical Research Communications 66 1237-1242. (doi:10. 1016/0006-291X(75)90491-X)

Soltys K, Dikdan G \& Koneru B 2001 Oxidative stress in fatty livers of obese Zucker rats: rapid amelioration and improved tolerance to warm ischemia with tocopherol. Hepatology 34 13-18. (doi:10.1053/ jhep.2001.25452)

Song Y, Wang J, Li Y, Du Y, Arteel G, Saari J, Kang Y \& Cai L 2005 Cardiac metallothionein synthesis in streptozotocin-induced diabetic mice, and its protection against diabetes-induced cardiac injury. American Journal of Pathology 167 17-26. (doi:10.1016/S00029440(10)62949-5)

Ståhlberg N, Rico-Bautista E, Fischer RM, Wu X, Cheung L, FloresMorales A, Tybring G, Norstedt G \& Tollet-Egnell P 2004 Femalepredominant expression of fatty acid translocase/CD36 in rat and human liver. Endocrinology 145 1972-1979. (doi:10.1210/en.20030874)

Sugimoto M, Koseki T, Hirayama A, Abe S, Sano T, Tomita M \& Soga T 2009 Correlation between sensory evaluation scores of Japanese sake and metabolome profiles. Journal of Agricultural and Food Chemistry 58 374-383. (doi:10.1021/jf903680d)

Sugimoto M, Hirayama A, Ishikawa T, Robert M, Baran R, Uehara K, Kawai K \& Soga T 2010 $a$ Differential metabolomics software for capillary electrophoresis-mass spectrometry data analysis. Metabolomics 6 27-41. (doi:10.1007/s11306-009-0175-1)

Sugimoto M, Wong D, Hirayama A, Soga T \& Tomita M $2010 b$ Capillary electrophoresis mass spectrometry-based saliva 
metabolomics identified oral, breast and pancreatic cancerspecific profiles. Metabolomics 6 78-95. (doi:10.1007/s11306-0090178-y)

Svoboda D, Azarnoff D \& Reddy J 1969 Microbodies in experimentally altered cells: II. The relationship of microbody proliferation to endocrine glands. Journal of Cell Biology 40 734-746. (doi:10.1083/ jcb.40.3.734)

Takaishi K, Duplomb L, Wang M-Y, Li J \& Unger RH 2004 Hepatic insig-1 or -2 overexpression reduces lipogenesis in obese Zucker diabetic fatty rats and in fasted/refed normal rats. PNAS 101 7106-7111. (doi:10.1073/pnas.0401715101)

Tang Y, Yang Q, Lu J, Zhang X, Suen D, Tan Y, Jin L, Xiao J, Xie R, Rane M et al. 2010 Zinc supplementation partially prevents renal pathological changes in diabetic rats. Journal of Nutritional Biochemistry 21 237-246. (doi:10.1016/j.jnutbio. 2008.12.010)
Wilson PA, Gardner SD, Lambie NM, Commans SA \& Crowther DJ 2006 Characterization of the human patatin-like phospholipase family. Journal of Lipid Research 47 1940-1949. (doi:10.1194/jlr. M600185-JLR200)

Yuan X, Waterworth D, Perry JRB, Lim N, Song K, Chambers JC, Zhang W, Vollenweider P, Stirnadel H, Johnson T et al. 2008 Population-based genome-wide association studies reveal six loci influencing plasma levels of liver enzymes. American Journal of Human Genetics 83 520-528. (doi:10.1016/j.ajhg.2008. 09.012)

Received in final form 15 May 2011

Accepted 14 June 2011

Made available online as an Accepted Preprint 14 June 2011 